\title{
The Development and Validation of Mathematical Thinking Beliefs (MTB) Instrument
}

\author{
Saoud Alhunaini ${ }^{1}$, Kamisah Osman ${ }^{1 *}$, Naser Abdurab ${ }^{2}$ \\ ${ }^{1}$ Faculty of Education, Universiti Kebangsaan Malaysia, MALAYSIA \\ ${ }^{2}$ Faculty of Education, International Islamic University Malaysia, MALAYSIA
}

Received 4 May 2021 - Accepted 18 August 2021

\begin{abstract}
Mathematical thinking beliefs are a significant element in supporting teachers' practices of learning and teaching school mathematics. Most prior researches on mathematics beliefs have focused on teachers' beliefs about learning and teaching mathematics in general. This research aimed to validate a Mathematical Thinking Belief instruments (MTB). The instrument was distributed to 523 mathematics teachers in Omani public schools. These teachers were asked to write their opinion in an instrument with a 5-point Likert scale. Exploratory factor analysis and confirmatory factor analysis have been applied to test the MTB using AMOS 25.0. All constructs show acceptable internal consistency reliability. The model meet a good model fit for the mathematical thinking beliefs measurement model through different fit index tests such as CMINDF, CFI, GFI, SRMR, RMSEA, and TLI. The results show that all indices of fit criteria were achieved. It is also indicated that acceptable validity, construct reliability and variance extracted values.
\end{abstract}

Keywords: mathematical thinking, teachers' beliefs, problem solving

\section{INTRODUCTION}

Belief as a social concept is considered as an intersection element between theory and practice. The belief has been presented by educational researches as an important concept that can be implemented to understand the teaching practices within and out of the classrooms. Beliefs also can be applied to explain the relationship between teachers' effectiveness and their knowledge in the teaching activities. Thus, mathematics teachers' beliefs have been studied in different aspects by the mathematics educational researchers to reach more understanding of their teaching practices (Alkharusi et al., 2017; Kul \& Celik, 2017; Purnomo et al., 2016).

Mathematics education researchers have developed several instruments to assess teachers' beliefs about mathematics and about learning mathematics in general. The researchers measured the reliability, validity, and normality of those instruments. The results showed many pieces of evidence about the relationship between the teachers' beliefs about mathematics and their teaching practices (Brady, 2014; Memnun \& Katranci,
2012; Peker \& Ulu, 2018). However, it is still little known about the mathematical thinking beliefs of Arabic teachers' because it is little known about instruments in the Arab world, especially in Oman, that has focused on the psychometrics of teachers' mathematical thinking beliefs instrument of descriptive statistics, normality, reliability, and validity. The current research tried to fill this gap through developing an instrument for assessing mathematics teachers' mathematical thinking beliefs.

\section{LITERATURE REVIEW}

Several researches in mathematics education have paid more attention to teachers' beliefs about mathematics to find accepted explanations and to expect teachers' teaching practices. They addressed teachers' beliefs to illustrate the complex relationship between teachers' knowledge and their educational effectiveness (Aljaberi \& Gheith, 2018; Haciomeroglu, 2013; Philipp, 2007). Beliefs were described as a complex construction which can influence the decisions of the teacher and also affect on their professional development. A lot of researches argued that teachers gain some of their beliefs during their engagement in mathematics and some of

(c) 2021 by the authors; licensee Modestum. This article is an open access article distributed under the terms and conditions of the Creative Commons Attribution License (http://creativecommons.org/licenses/by/4.0/).

\Saod.alhunaini@moe.om $\square$ kamisah@ukm.edu.my (*Correspondence) $\square$ nalareqe@yahoo.com 


\section{Contribution to the literature}

- This study introduces an instrument for assessing teachers' mathematical thinking beliefs which can be applied as a self-assessment or pre-assessment instrument for mathematics teachers and teaching institutions.

- This study contributes to link the definition of mathematical thinking with the educational beliefs of mathematics teachers.

- This study provides information specifically on the five main skills of mathematical thinking and teachers' beliefs.

them obtained during their learning of mathematics in schools. Thus, measuring teachers' beliefs is essential, and at the same time is important to improve the classroom assessment practices (Alkharusi et al., 2017; Kul \& Celik, 2017; Pajares, 1992).

Philipp (2007) defined beliefs as psychologically-held understandings, structure, or suggestions related to the world that are supposed to be true. Beliefs are different from knowledge because they can be measured with a scale of degrees of perception and does not need to be consent. Moreover, the system of beliefs can be organised as groups of concentrating nearby a based on particular subject or idea. Beliefs can be used by people to gain more understanding about themselves and their surrounding. They affect the person's way of accepting or rejecting the new information (Pajares, 1992). Thus, beliefs were widely used as an essential variable to understand teachers' practices in the classrooms (Hongboontri \& Keawkhong, 2014).

\section{Mathematical Thinking}

Mathematical thinking is a term which was presented as one of the most important terms in mathematics educational researches. It has been widely used in mathematics education research as a significant indicator for assessing mathematical skills to decide what should be developed in students' abilities. Mathematical thinking should link to students' abilty to logical thinking, mathematical connections, problem solving and mathematical communications (Saragih \& Napitupulu, 2015). In addition, some organisations like the Organisation for Economic Co-Operation and Development (OECD) has described mathematical thinking as a process that requires to set apart between different types of mathematical statements like theorems, definitions conjectures, hypotheses, examples, condition assertion, posing of high order problems, and using logic to assess the answers (OEDC, 2000). The researchers' efforts have revealed a huge amount of information can be used to develop students' learning of mathematics. For example, Saragih and Napitupulu (2015) found that problem solving and mathematical communication influence the students' mathematical thinking.

Initially, thinking in mathematics was known as a method of thinking which contains specific mental processes, dynamics, and operations related to mathematics doing (Burton, 1984). Whereas, nowadays, researchers introduced a definition of mathematical thinking which became wider to cover most aspects that are related to mathematics doing and learning within and out of classrooms. Pourdavood et al. (2020) described mathematical thinking as the mental process supported by mathematical knowledge and a specific type of readiness towards achieving a solution to the problem. The definition of mathematical thinking became more relevant to mathematics education since a great deal of researches in mathematics education were focused on student mathematical thinking (Burte et al., 2019; Saragih \& Napitupulu, 2015). A Number of previous researchers have mentioned that mathematical thinking is related to mathematical skills: problemsolving, proof and reasoning, representation, mathematical communications and mathematics connections (e.g., Anthony et al., 2015; Saragih \& Napitupulu, 2015; Yong \& Sam, 2008). These mathematical skills were determined as NCTM (2000) standards for school mathematics in the National Council of Teaching Mathematics.

The previous researches revealed that the mathematical thinking skills cannot be separated from one another because each skill is connected to other skills. For instance, Celiki and Ozdemir (2020) investigated the relationship among mathematical thinking sup-dimensions (mathematical thinking, reasoning, higher order thinking and problem-solving). The results revealed that there is a significant relationship between mathematical thinking supdimensions mathematical thinking, reasoning, higher order thinking and problem-solving. Pourdavood et al. (2020) studied the impact of students' mathematical communication on their abilities in problem solving and reasoning. The finding showed that students' verbal communication help to improve their abilities in problem solving and reasoning. Mccluskey et al. (2016) indicated that reasoning play important role in students' ability to solve mathematics problems.

Problem solving has been considered as the peak level of mental skills (Palraj et al., 2017; Uyangör, 2019). It helps students to increase their experience in all strategies of general mathematics (Celiki \& Ozdemir, 2020). It was described by Abdullah et al. (2019) as a 
process where the individual faces an unfamiliar situation through the using of prior skills, knowledge, and understanding to meet the demands of an unfamiliar situation. Problem solving was known as a crucial life skill that requires a range of processes, including analysis, thinking, assessment, interpretation, prediction, and reflection. It is either a fundamental component or an overall goal of the school math curriculum in many countries such as Malaysia, Singapore, Hong Kong, England, and Australia (Abdullah et al., 2019; Acar-Erdol \& Y1ld1z, 2018; Anderson, 2009). Several researches reported that many teachers believe that problem solving is useful to improve the students' mathematical thinking skills and also to develop the students' real life skills (Palraj et al., 2017; Xenofontos \& Kyriakou, 2017; Yavuz \& Cansız, 2019).

Anderson's (2009) results showed that prblem sovling plays a significant role in students' mathematical thinking because problem solving requires thinkg skills like understanding, planing, applying and evaluating the answers. Palraj et al. (2017) indicated that problem solving requires teachers to train their students on thinking skills to be able to solve problems. The finding showed that teachers' beliefs about problem solving influence the way of their using of problem solving. For example, teachers who believe that problem solving needs students to memorize facts more than thinking, apply the traditional teaching methods. Yavuz and Cansiz (2019) revealed that there is a strong relationship between students' mathematical thinking and their abilities to solve mathematical problems. Uyangör (2019) showed that problem solving skills support the students' mathematical thinking.

Mathematical representation can be described as a process of converting mathematical ideas from one form to another. This can help students to gain better understanding of mathematical ideas (Maoto et al., 2018). Lesh et al. (2003) categorised representation for mathematical ideas into five sets: manipulative models, real-world situation, written symbols, pictures, and oral/written language. These representations can play a significant role in mathematical activities (Anthony et al., 2015). One the other hand, NCII (2016) classified mathematical representations into three main phases: Concrete representations, pictorial or visual representations and abstract or symbolic representations.

According to NCTM (2000), mathematical representations can be used by students to record, organise, and communicate mathematical ideas. Consequently, mathematical representations help students to improve their understanding of mathematical concepts and mathematical problems (NCII, 2016). In other words, students who can move between or among different kinds of representations can improve their understanding and retention of mathematical concepts. Moreover, students' use of representations can be linked with the mathematical experience of students and teaching methods used by teachers (Chigeza, 2013). On the other hand, some researches showed that students who have difficulties in translating concepts from one representation to another also have difficulties in understanding calculations and solving problems (Chigeza, 2013; Sari \& Rosjanuardi, 2018).

Reasoning and proof play important role in mathematics learning because they improve the learners' abilities to judge whether a statement is true or not. They also improve learners' accuracy when they solve or present mathematics problems (Celiki \& Ozdemir, 2020; Maoto et al., 2018). The proving process needs high-level thinking skills, precisely, and mathematical reasoning skills (Mumcui \& Aktürk, 2017; Pourdavood et al. 2020; Salazar, 2012). Mathematical reasoning and proof provide substantial opportunities to improve quick insights into a wide range of phenomena. Students' ability in reasoning can be explored in their explanation, justification and their mental processes (Mccluskey et al., 2016). Some researchers like Mumcui and Aktürk (2017) mentioned that mathematical reasoning contains the abilities of generalizing, abstraction and modelling. People who think and reason analytically tend to observe structure, patterns, or differences in both the real world and mathematical situations. Reasoning and proof help to study all branches of mathematics such as statistics, algebra and probability (Siemon et al., 2017). Developing mathematical reasoning of students can improve their abilities in the natural and abstract thinking in a coherent path (Reyes-Cedeno et al., 2019). This could develop and evaluate their abilities to use the mathematical arguments and proofs. They are formal ways of expressing certain types of reasoning and justification through exploring phenomena, using mathematical guesswork and justifying the results in all areas of content (NCTM, 2000).

In general, communication helps to emerge ideas as objects of refinement, reflection, modification and discussion. Additionally, the process of communication supports constructing and making sense of the ideas and making them general. Mathematical communication can be described as a way of sharing ideas and clarifying understanding. Mathematical communications translate ideas into objects of reflection, discussion, revision and refinement. If students have been challenged to communicate mathematically, this may help their using of mathematical language to be more precise, clear and convincing (NCTM, 2000). Mathematical communications were classified as one of the high-level skills of mathematical thinking (Saragih \& Napitupulu, 2015). Moss and Archer (2014) suggested four communication skills: vocabulary; verbal presentation; 
identifying facts and ideas, skills and writing skills and choosing appropriate vocabulary skills.

Mathematics is not a collection of separate strands or standards, even though it is often partitioned and presented in this manner. Instead, mathematics is an integrated field of study. Mathematical connections can be divided into internal connections, i.e., connections between mathematics branches and external connections, i.e., connections between mathematics and other subjects and the real world. It seems that both external and internal connections request students to work their metacognitive skills to identify the aims of the mathematical instruments they are studying and to recognise subfields along the way to the solution. Students' mathematical connection ideas make their understanding deeper and more durable because they come to view mathematics consistent as a whole (Anthony et al., 2015; Yong \& Sam, 2008). Furthermore, they see mathematical linkages in the productive interaction among mathematical subjects, in contexts that relate mathematics with other subjects, and in their own experience and interests. Through teaching that emphasizes the interdependence of mathematical ideas, students learn mathematics and the advantage of mathematics (NCTM, 2000).

Mathematical connections are not only essential to increase the students' mathematical understanding, but it is also imperative to be clear for mathematics teachers. They support the teaching practices of teachers and also may affect their beliefs positively about mathematics and mathematics teaching. They encourage students to gain the shared vision of mathematics which increases in parallel with the growth of the student's experience of solving problems in mathematics (Ormond, 2016; Yong \& Sam, 2008). They help students to link their previous mathematical knowledge and skills with the new ones. They also help to build their own view of mathematics through connecting different mathematics branches to build an organized construction of mathematical idea (NCTM, 2000).

\section{Measuring Teachers' Beliefs about Mathematics}

Many researches tried to determine teachers' beliefs about mathematics. They used quantitative and qualitative methods to collect data. Most of the quantitative researches used questionnaires of four or five points of Likert scales. The instruments were differed in their dimensions depending on the definition confirmed in the studies. For example, some researches classified teachers' mathematical beliefs into traditional beliefs and alternative beliefs. Some another researches divided mathematical beliefs about mathematics learning, beliefs about mathematics teaching and beliefs about the effectiveness of learning and teaching mathematics. While, some other researches defined beliefs about mathematics nature and mathematics assessment as dimensions of beliefs about mathematics (Aljaberi \& Gheith, 2018; Memnun \& Katranci, 2012; Purnomo, 2017).

The instrument that was used in (Aljaberi \& Gheith, 2018) was composed of 37 items. The reliability of the instrument was determined by calculated the coefficient Cronbach's Alpha for the dimensions and overall. The values were 0.90 for overall, 0.77 for beliefs about the nature of mathematics, 0.77 for beliefs about mathematics teaching and 0.82 for beliefs about learning mathematics. Furthermore, several instruments aimed to measure teachers' beliefs about mathematics were developed using Confirmatory Factor Analysis (CFA). The content validity of the instruments was performed by presenting the instrument to experts in mathematics education and educational evaluation. Further, the instruments were tested for reliability by calculated the coefficient Cronbach's alpha for the dimensions and overall and half-spilt (Purnomo, 2017). To test (CFA) of the instruments, researchers used the data $\left(X^{2} / S D\right)$ ChiSquare/ freedom degree, (RMSEA) Root Mean Square Error of Approximation, (IFI) Incremental Fit Index, (TLI) Tucker-Lewis Index, and (CFI) Comparative Fit Index to check the model compatibility. The results showed that the instrument reaches a good fit. Table 1 shows the results of CFA of mathematical beliefs instruments in some previous studies. However, most of those instruments were designed to assess teachers' beliefs about mathematics in general and did not focus on the of teachers' beliefs about mathematical thinking. Table 1 indicates examples of using CFA valued and coefficients of reliability of mathematical beliefs instruments.

There were several researches which have studied beliefs about some skills of mathematical thinking such as beliefs about problem-solving, representation or proofs. For example, Salazar (2012) used a questionnaire to measure students' beliefs about mathematical proofs. Bal (2015) used a 5-point Likert scale of problem-solving beliefs to gather data about students' problem-solving beliefs. The instrument was classified into mathematics skills, problem understanding, mathematics place, mathematics importance and problem-solving skills. Moreover, the previous instruments were written in

Table 1. CFA values and coefficients of Reliability of mathematical beliefs instruments

\begin{tabular}{|c|c|c|c|}
\hline Study & Reliability coefficient & CFA values & Country of applying \\
\hline (Peker \& Ulu, 2018) & Cronbach alpha 0.83 & $\chi^{2} / \mathrm{SD}=1.695, \mathrm{RMSEA}=0.053, \mathrm{TLI}=0.91, \mathrm{IFI}=0.93, \mathrm{GFI}=0.92$ & Turkish \\
\hline (Purnomo, 2017) & Cronbach alpha 0.782 & $\begin{array}{l}\chi^{2} / \mathrm{df}, \mathrm{p} \text { value, NC, RMSEA, SRMR, GFI, AGFI, NFI, TLI } \\
\text { and CFI }\end{array}$ & Indonesia \\
\hline (Mistima et al., 2011) & Cronbach alpha 0.81 & $\begin{array}{l}\mathrm{df}=127, \mathrm{p}=.020, \mathrm{CMINDF}=1.633, \mathrm{TLI}=.920, \mathrm{CFI}=.934 \\
\mathrm{GFI}=.922 \text { and } \mathrm{RMSEA}=.049\end{array}$ & Malaysia \\
\hline
\end{tabular}


non-Arabic language. For example, Salazar (2012) used an instrument in Filipino language. Bal (2015) applied an instrument in Turkish. This indicated the requirement to develop an instrument for assessing teachers' beliefs about mathematical thinking using the Arabic language to be applied in the Arabic area, especially in Oman.

People's culture plays an important role in their beliefs in general. Culture gathers people into shared attitudes, values, standards and thinking ways. However, it is difficult to define individuals within a particular confines culture, because individuals belong to different sub-groups, containing ethnicity, religion, language, linguistic background, etc (Al-Mahrooqi et al., 2015). For instance, Hongboontri and Keawkhong (2014) found that teachers' culture can direct their teaching practices. Gebney (2014) indicated that teachers' culture reacts with their beliefs about mathematics. The individual's habits and self-monitoring can be reflected in their using of mathematics learning processes. Each language has something that distinguishes it from other languages. For example, Arabic language contains many rules that are not applicable in many other languages like the formulation of verbs is affected by gender and number of people. Thus, it is significant to pay attention to teachers' culture and language in developing instruments for measuring teachers' beliefs (Karaman \& Sahin, 2017).

Consequently, it is required to build an instrument to measure teachers' beliefs about all five skills of mathematical thinking in Arabic. The current research developed an instrument to measure teachers' belief about mathematical thinking and was tested with CFA. The instrument covered teachers' beliefs about all five mathematical thinking skills: problem-solving, mathematical connections, reasoning and proofs, representation, and mathematical communication. The instrument of teachers' Mathematical Thinking Beliefs (MTB) was built depending on previous instruments of mathematical beliefs and (NCTM, 2000) standards of school mathematics which were based on the definition of mathematical thinking confirmed in this study.

\section{Mathematics Education in Oman}

In Oman, there is increased attention from educators to enhance students' academic achievement in mathematics. This attention increased because the results from international tests of academic achievement like TIMSS have revealed that the academic achievement in mathematics of Omani students is much lower compared to students' achievement in several Middle East countries (Alkharusi et al., 2017). The Ministry of Education in Oman tried to increase the quality of mathematics learning and teaching by reforming the educational system. For example, teachers who teach mathematics in grades 5-12 in Oman must have the qualification or a general university degree with an educational diploma (UNESCO, 2010). The mathematics curriculum in Oman has been developed into a set of six standards: number and number theory, number operations, data management and probabilities, prealgebra and algebra, measurement, and geometry. All learning objectives are linked to a specific level of achievement in the standards for each grade level (AlMaskar et al., 2015).

\section{OBJECTIVE OF THE STUDY}

The objectives of this study are to:

1) Develop an instrument for teachers' mathematical thinking beliefs.

2) Test the reliability of SEM of teachers' mathematical thinking beliefs instrument.

3) Test the validity of SEM of teachers' mathematical thinking beliefs instrument.

4) Test the G factor of SEM of teachers' mathematical thinking beliefs instrument.

\section{METHODOLOGY}

\section{Research Design}

This study was designed as a survey study with firstorder factor structure model as it was referred by (Keith et al., 2006). The research design applied a quantity tool that is widely used in social sciences which is a series of items or questions that should be responded to by participants. It is also called a self-reported questionnaire because the applicants mostly respond to statements or questions related to themselves, and to their attitudes, beliefs, and so on (Privitera, 2014).

\section{Sample of the Study}

The sample of this study was 537 mathematics teachers of the classes in grades 5-12 in Omani public schools, 265 of them were males and 272 were females. The teachers' experience of teaching was between 1 and 28 years. The participations were randomly selected. First the researchers chose seven educational governorates which are under the Ministry of Education in Oman to ensure that all local environments in Oman will be represented, such as desert, agricultural, coastal, mountainous areas and large cities, all from which mathematics supervisors were randomly selected. Each supervisor randomly chose 20 mathematics teachers and asked them to write their response to the instrument of Mathematical Thinking Beliefs (MTB).

\section{Instrument}

The instrument of the study was developed as a selfreported questionnaire. The questionnaire was developed by the researchers. Initially, it is composed of 25 items on a 5-point Likert scale ranging from $(1=$ strongly disagree $)$ to $(5=$ strongly agree $)$. The items 
were written by adapting some items from some previous instruments of teachers' mathematical beliefs which have been written within and generally contexts mathematics (Bal, 2015; Bates et al., 2011; Philipp et al., 2002; Ünlü \& Ertekin, 2013). Some items were extracted from the results of qualitative researches (Hudson et al., 2015; Lui \& Bonner, 2016). The items were adapted by linking teachers' mathematical beliefs and mathematical thinking skills depending on the standards of school mathematics (NCTM, 2000). Further, it was also taken into consideration that the contents of the items were proportional to the contents of the skills taught within the mathematics curricula of the Ministry of Education in Oman for grades 5-10. Most of the items were written as positive ones. They were written to determine the positivity or negativity of the teacher's beliefs related to his/her selections. For example, if a teacher chooses agree or strongly agree, this means that he/she holds a positive belief related to the item. Whereas, the choosing of disagree or strongly disagree means that he/she holds a negative belief.

The items were distributed into 5 dimensions (problem-solving, mathematical connections, reasoning and proofs, representation, and mathematical communication). All items of the instrument were drafted in Arabic because all mathematics teachers' in Omani public schools speak Arabic language. This helped to reflect some Arabic culture into items through the wording of the items. The items related to the teachers' beliefs about problem solving cover the role of problem solving in mathematics learning and the essential requirements to achieve the goals. The beliefs about mathematical representation items focus on the usage of representations in mathematics by learners and teachers. Teachers' beliefs about proofs and reasoning were design to describe the teachers' belief about the importance of reasoning and proofs as basic skills of thinking in mathematics. The mathematical communication beliefs items were formulated to describe the benefits of mathematical communications for students to establish their mathematical idea clearly, where mathematical connections beliefs items described how mathematics connections help to link mathematical ideas to gain clear understanding of mathematics subjects. Table 2 shows the dimensions and the number of items.

Content validity of the instrument's items of mathematical thinking beliefs was documented through presenting it to a group of specialists in educational evaluation, mathematics education and educational psychology. They were asked to check the language clarity, suitability, and wording of all the items for using them with the Arabic mathematics teachers, and their comprehensiveness and significance to the construction being assessed. Their feedbacks were applied to edit the items. The mentioned opinions showed that most items were appropriate and expressive for Arabic mathematics
Table 2. The number of items in each dimension of the Mathematical Thinking Beliefs instrument

\begin{tabular}{lc}
\hline Mathematical Thinking Beliefs Dimension & Number of Items \\
\hline Problem-Solving (PS) & 5 \\
Mathematical Representation (MR) & 5 \\
Reasoning and Proofs (RP) & 5 \\
Mathematical Communications (MCom) & 5 \\
Mathematical Connections (MCon) & 5 \\
Total of items & 25 \\
\hline
\end{tabular}

teachers, were related to the mathematics content of grades 5-10 and were related to the subject being evaluated. However, they suggested some modifications for some items.

\section{Data Analysis}

The Skewness and Kurtosis were used to test the normality of items of each measurement instrument. Factor should be located within the acceptable level, i.e., $<3$ for Skewness and < 7 for Kurtosis (Kline, 2015). Confirmatory Factor analysis (IBM AMOS Statistics 25.0) were addressed to test the model of mathematical thinking beliefs. The correlation matrix among items of the instrument (mathematical thinking beliefs) was investigated at the beginning of any step. If the value of each correlation is less than 0.30 , the orthogonal methods of factor analysis should be used, whereas if it is equal or above 0.30 , the oblique methods should be used (Brown, 2014; Byrne, 2016; Tabachnick \& Fidell, 2007).

\section{FINDINGS AND DISCUSSION}

\section{Normal Distribution and Reliability for the Mathematical Thinking Beliefs Items}

Table 3 shows that indices of Skewness $\leq(-/+3)$ and Kurtosis $\leq(-/+7)$ revealed that all items of all dimensions are located within an acceptable threshold of Skewness $\leq(-/+3)$ and Kurtosis $\leq(-/+7)$ given by Kline (2015), indicating that all items of Mathematical Thinking Beliefs instrument are normally distributed. Further, the coefficients of the correlation between all items and their dimensions are more than 0.30 , which indicated that all items are positively related with the dimensions. Furthermore, coefficients of Cronbach's alpha for all dimensions between 0.662 and 0.794 , which is acceptable as a conventional standard for reliability (Hair et al., 2014). Table 3 also indicates that all the dimensions of mathematical thinking beliefs got a mean more than four (4.21-4.45) which means that teachers held strong and positive mathematical thinking beliefs.

\section{Confirmatory Factor Analysis for Mathematical Thinking Beliefs (MTB)}

The MTB model (Figure 1) was measured by five components: Problem solving (five items), representations (five items), reasoning and proof (five items), mathematical communication (five items), and mathematical connection (five items). 
Table 3. Skewness and Kurtosis, and Reliability of Dimensions of Mathematical Thinking Beliefs

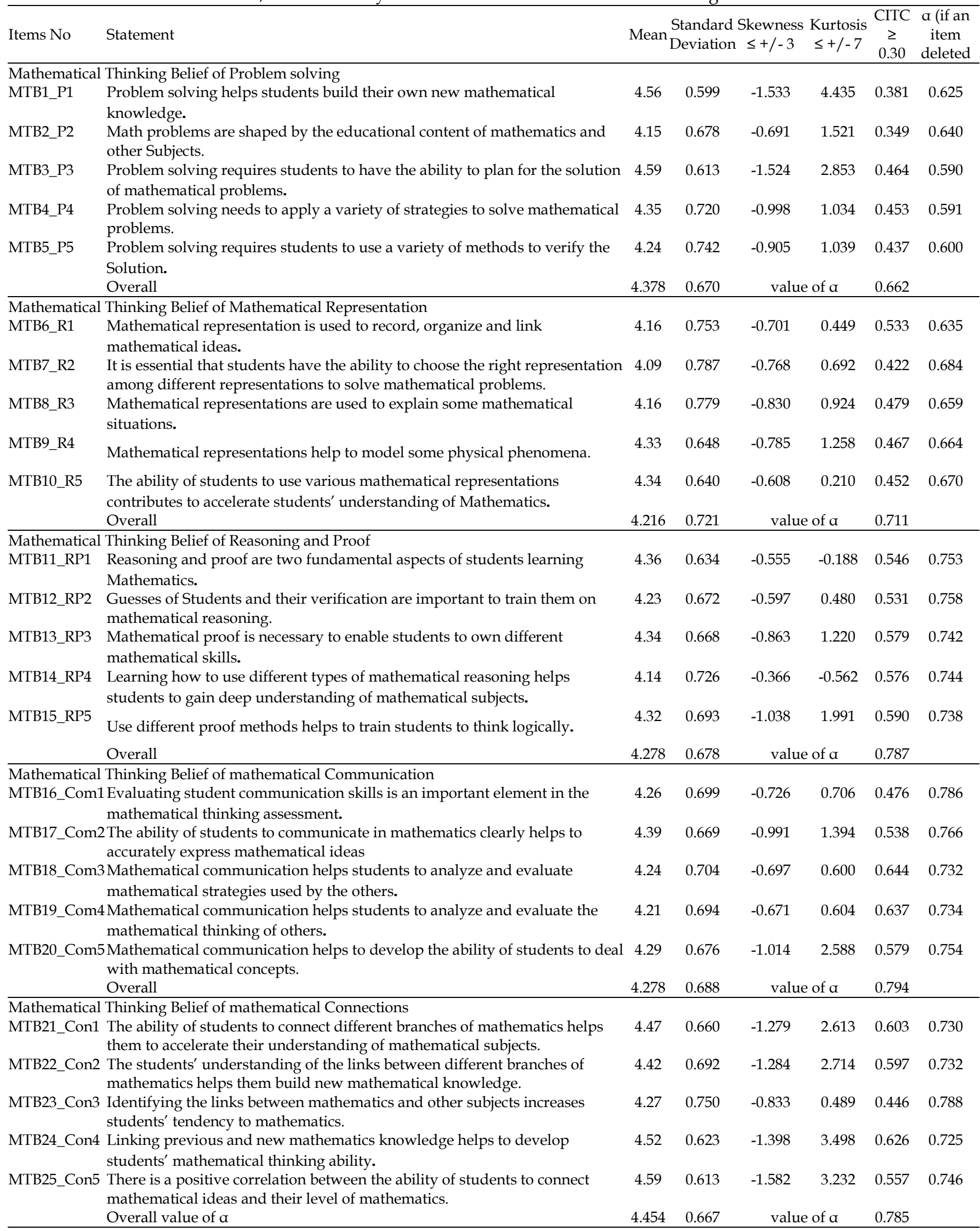

As presented in Figure 1 and Table 4, the goodness of fit indices for the first order CFA of MTB model, indicates the fit statistics that are less than the required criteria as Comparative Fit Index $(\mathrm{CFI})=0.888$ (does not reach the threshold of $>0.90$ ), Incremental Fit Index (IFI) $=0.889$ (does not pass the threshold of $>0.90)$, Tucker Lewis Index $(\mathrm{TLI})=0.874$ (less than the threshold of $>$ 0.90), and Goodness of Fit index (GFI) $=0.896$ (does not 


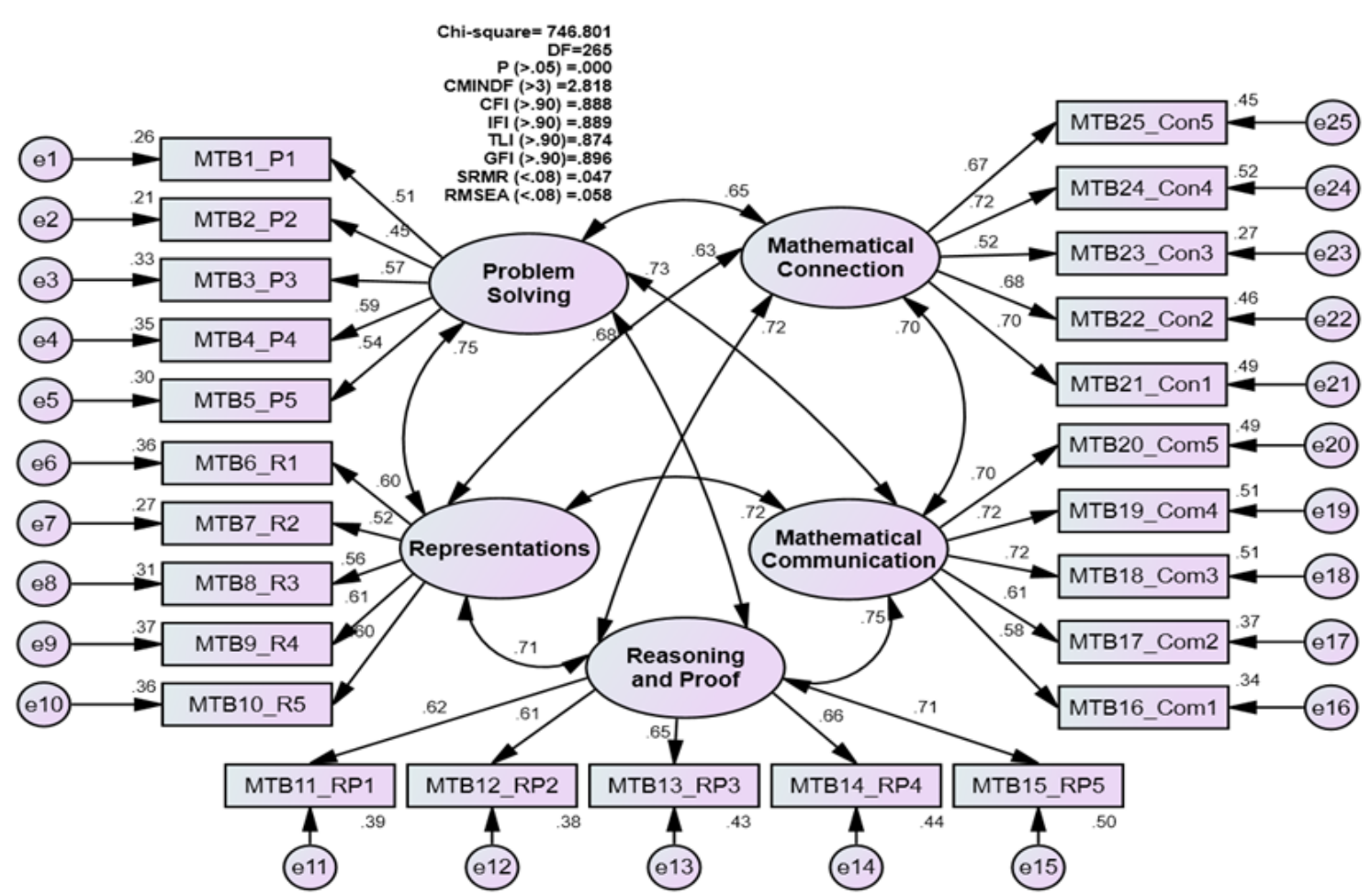

Figure 1. Confirmatory factor analysis for MTB (Original Model)

Table 4. Goodness fit indices for MTB

\begin{tabular}{llcccc}
\hline \multicolumn{2}{l}{ Indices } & $\begin{array}{c}\text { Required } \\
\text { Scores }\end{array}$ & $\begin{array}{c}\text { First attempt: } \\
\text { Baseline Model }\end{array}$ & $\begin{array}{c}\text { Second attempt: } \\
\text { Re-Specified Model }\end{array}$ & $\begin{array}{c}\text { Second Order } \\
\text { CFA }\end{array}$ \\
\hline 1 & Chi-Square & - & 746.801 & 510.108 & 523.476 \\
2 & DF (Degree of Freedom) & - & 265 & 217 & 222 \\
3 & P (Probability) & $(\leq 0.05)$ & 0.000 & .000 & 0.000 \\
4 & CMINDF (Normed Chi-Square) & $(<3)$ & 2.818 & 2.351 & 2.358 \\
5 & CFI (Comparative Fit Index) & $(>0.90)$ & 0.888 & 0.924 & 0.922 \\
6 & IFI (Incremental Fit Index) & $(>0.90)$ & 0.889 & 0.925 & 0.922 \\
7 & TLI (Tucker-Lewis Index) & $(>0.90)$ & 0.874 & 0.911 & 0.911 \\
8 & GFI (Goodness of Fit Index) & $(>0.90)$ & 0.896 & 0.923 & 0.920 \\
9 & SRMR (Squared Root Mean Residual) & $(<0.08)$ & 0.047 & 0.044 & 0.044 \\
10 & RMSEA (Root Mean Squared Error Approximation) & $(<0.08)$ & 0.058 & 0.050 & 0.050 \\
\hline
\end{tabular}

reach the threshold of $>0.90$ ). Moreover, the magnitude of some item loadings is less than 0.50 as the least acceptable value. Subsequently, this baseline/generic model needs to be improved to obtain a plausible model, which was done by removing items with loading below 0.50 as the less theoretically contribute in shaping and modelling its respective construct. The re-specified model contained the previous model without item (MTB1_P2) from the problem-solving construct and item (MTB21_Con1) from the Mathematical Connection construct, as it was required for the correlation with several items as Modification Indices (MI) in AMOS.

To reach the acceptable goodness of fit statistics, error terms are correlated between e 9 and e10, e25 and e24, e19 and e18, which are statistically significant (T-value $\geq$ 1.964 and P-value $\leq 0.05)$, as suggested by the Modification Indices in Amos, followed by theoretical justification later on. Further, in Figure 2 and Table 4, goodness fit indices for first order of MTB as a respecified model, which disclose that its fit statistics are located within the acceptable criteria as Normed Chi-
Squared CMINDF $=2.351, \mathrm{CFI}=0.924, \mathrm{IFI}=0.925, \mathrm{TLI}=$ $0.911, \mathrm{GFI}=0.923, \mathrm{SRMR}=0.044$, and $\mathrm{RMSEA}=0.050$.

Table 5 indicated that Composite Reliability (CR) for each construct in the hypothesised model meets the acceptable criteria of 0.70 , while Average Variance Extracted (AVE) does not meet the acceptable criteria of 0.50 . However, further analysis can be performed, as long as the CR was achieved without meeting AVE. If AVE is less than 0.5 , but the CR is greater than 0.6, the convergent validity of the construct will still be adequate (Fornell \& Larcker, 1981a, 1981b). Particularly, the issues of construct validity (Convergent Validity and Discriminant Validity) for the MTB model are beyond the objective of the current research. Covariances Table 6 among the five constructs of the model of MTB are statistically significant (T-value $\geq 1.964$ and P-value $\leq$ 0.05). 


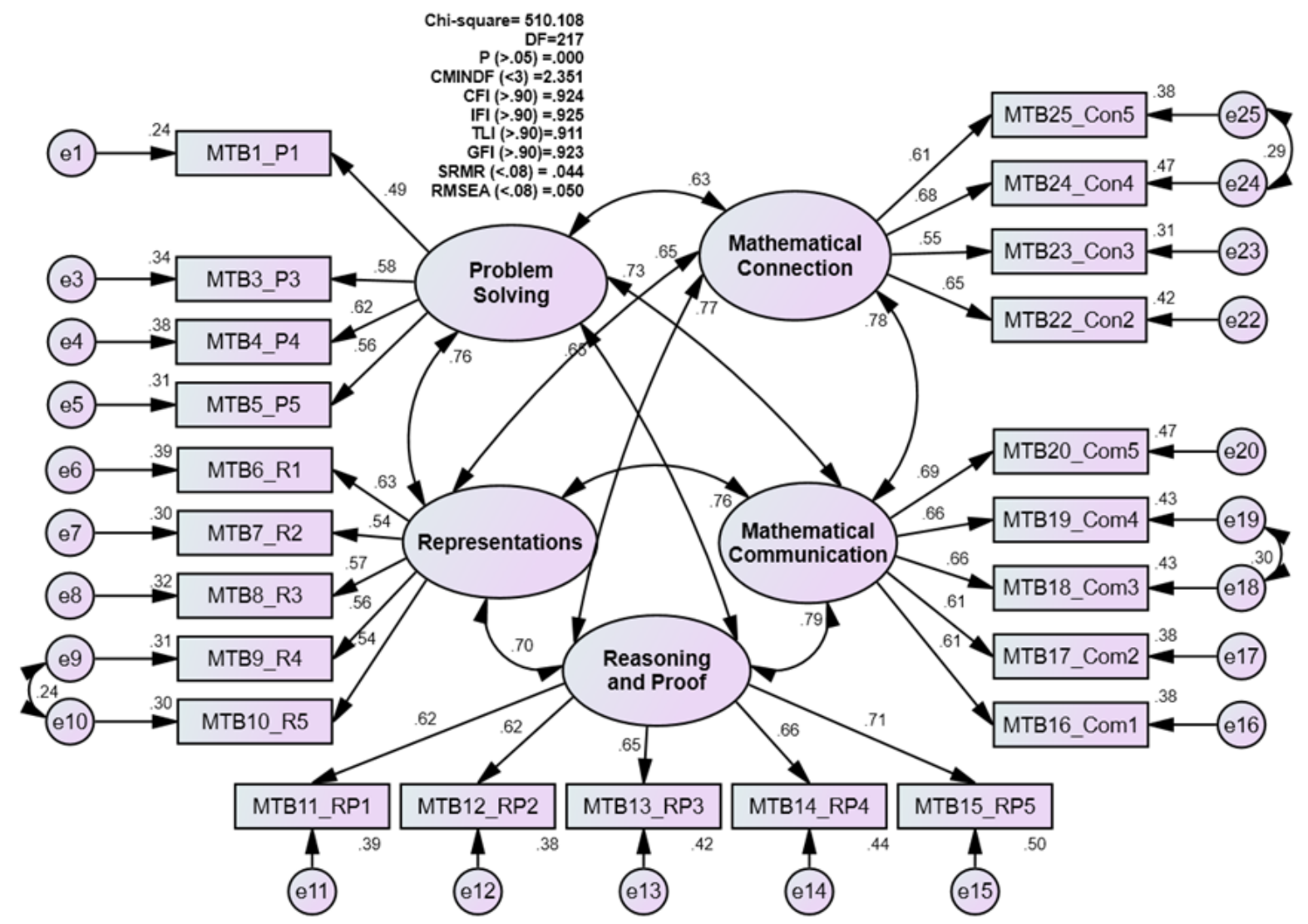

Figure 2. Confirmatory factor analysis for MTB (Modified Model)

Table 5. Results of Parameters of Measurement Model of MTB

\begin{tabular}{|c|c|c|c|c|c|c|c|c|c|}
\hline Construct & Items & B & SE & T-Value & $\mathrm{P}$ & $\begin{array}{c}\text { Factor } \\
\text { loading }\end{array}$ & SMC & $\mathrm{CR}$ & AVE \\
\hline Mathematical & Problem solving & 1.00 & & & & 0.80 & 0.64 & 0.93 & 0.73 \\
\hline Thinking & Representations & 1.67 & 0.21 & 7.92 & 0.00 & 0.83 & 0.69 & & \\
\hline \multirow{3}{*}{ Beliefs } & Reasoning and Proof & 1.46 & 0.18 & 8.12 & 0.00 & 0.86 & 0.74 & & \\
\hline & Mathematical Communication & 1.83 & 0.21 & 8.52 & 0.00 & 0.92 & 0.84 & & \\
\hline & Mathematical Connection & 1.35 & 0.17 & 7.88 & 0.00 & 0.84 & 0.71 & & \\
\hline \multicolumn{10}{|l|}{ Component } \\
\hline \multirow[t]{4}{*}{ Problem solving } & MTB1_P1 & 1.00 & - & - & - & 0.49 & 0.24 & 0.648 & 0.32 \\
\hline & MTB3_P3 & 1.22 & 0.14 & 8.46 & 0.00 & 0.58 & 0.34 & & \\
\hline & MTB4_P4 & 1.53 & 0.16 & 8.75 & 0.00 & 0.62 & 0.38 & & \\
\hline & MTB5_P5 & 1.43 & 0.17 & 8.33 & 0.00 & 0.56 & 0.31 & & \\
\hline \multirow{5}{*}{ Representations } & MTB6_R1 & 1.00 & - & - & - & 0.627 & 0.39 & 0.71 & 0.32 \\
\hline & MTB7_R2 & 0.91 & 0.09 & 9.96 & 0.00 & 0.54 & 0.30 & & \\
\hline & MTB8_R3 & 0.94 & 0.09 & 10.28 & 0.00 & 0.57 & 0.32 & & \\
\hline & MTB9_R4 & 0.77 & 0.08 & 10.11 & 0.00 & 0.56 & 0.32 & & \\
\hline & MTB10_R5 & 0.74 & 0.08 & 9.85 & 0.00 & 0.54 & 0.30 & & \\
\hline \multirow[t]{5}{*}{ Reasoning and Proof } & MTB11_RP1 & 1.00 & - & - & - & 0.62 & 0.39 & 0.79 & 0.43 \\
\hline & MTB12_RP2 & 1.05 & 0.09 & 11.54 & 0.00 & 0.62 & 0.38 & & \\
\hline & MTB13_RP3 & 1.10 & 0.09 & 12.03 & 0.00 & 0.65 & 0.42 & & \\
\hline & MTB14_RP4 & 1.22 & 0.10 & 12.23 & 0.00 & 0.66 & 0.44 & & \\
\hline & MTB15_RP5 & 1.25 & 0.10 & 12.80 & 0.00 & 0.71 & 0.50 & & \\
\hline Mathematical & MTB16_Com1 & 0.93 & 0.08 & 12.40 & 0.00 & 0.61 & 0.38 & 0.78 & 0.42 \\
\hline \multirow[t]{4}{*}{ Communication } & MTB17_Com2 & 0.89 & 0.07 & 12.40 & 0.00 & 0.614 & 0.377 & & \\
\hline & MTB18_Com3 & 1.00 & 0.08 & 13.09 & 0.00 & 0.66 & 0.44 & & \\
\hline & MTB19_Com4 & 0.98 & 0.08 & 13.02 & 0.00 & 0.66 & 0.43 & & \\
\hline & MTB20_Com5 & 1.00 & - & - & - & 0.69 & 0.47 & & \\
\hline Mathematical & MTB22_Con2 & 1.19 & 0.11 & 10.92 & 0.00 & 0.65 & 0.42 & 0.72 & 0.39 \\
\hline \multirow{3}{*}{ Connection } & MTB23_Con3 & 1.11 & 0.11 & 9.83 & 0.00 & 0.55 & 0.31 & & \\
\hline & MTB24_Con4 & 1.13 & 0.08 & 13.95 & 0.00 & 0.68 & 0.47 & & \\
\hline & MTB25_Con5 & 1.00 & - & - & - & 0.61 & 0.38 & & \\
\hline
\end{tabular}

Key: $\mathrm{B}=$ Unstandardized Estimation, $\mathrm{SE}=$ Standard Error, $\mathrm{P}=$ Probability Value, $\mathrm{SMC}=$ Squared Multiple Regression, $\mathrm{CR}=\mathrm{Composite}$ Reliability , AVE = Average Variance Extracted 
Table 6. Results of Covariance among Constructs of MTB Model

\begin{tabular}{llcccccc}
\hline Construct & Construct & B & SE & T-Value & P & R & SMC \\
\hline Mathematical Communication & Reasoning and Proof & 0.144 & 0.016 & 9.192 & 0.00 & 0.791 & 0.62 \\
Representations & Reasoning and Proof & 0.130 & 0.016 & 8.223 & 0.00 & 0.701 & 0.49 \\
Mathematical Connection & Mathematical Communication & 0.135 & 0.015 & 8.812 & 0.00 & 0.777 & 0.60 \\
Mathematical Connection & Representations & 0.116 & 0.015 & 7.660 & 0.00 & 0.654 & 0.42 \\
Problem solving & Mathematical Communication & 0.099 & 0.013 & 7.476 & 0.00 & 0.734 & 0.53 \\
Problem solving & Representations & 0.104 & 0.014 & 7.230 & 0.00 & 0.756 & 0.57 \\
Representations & Mathematical Communication & 0.166 & 0.019 & 8.824 & 0.00 & 0.758 & 0.57 \\
Mathematical Connection & Problem solving & 0.069 & 0.010 & 6.657 & 0.00 & 0.631 & 0.39 \\
Mathematical Connection & Reasoning and Proof & 0.114 & 0.013 & 8.466 & 0.00 & 0.769 & 0.59 \\
Problem solving & Reasoning and Proof & 0.075 & 0.011 & 6.975 & 0.00 & 0.654 & 0.42
\end{tabular}

Key: B = Unstandardized Estimation, SE = Standard Error, $\mathrm{P}=$ Probability Value, $\mathrm{r}=$ Correlation, SMC = Squared Multiple Regression

Table 7. Results of Shared Variance (SV), Squared Multiple Correlation (SMC) and Square Root of AVE

\begin{tabular}{lcccc}
\hline Constructs & 1 & 2 & 3 & 4 \\
\hline Mathematical Communication & 0.65 & & & \\
Reasoning and Proof & 0.62 & 0.65 & & \\
Representations & 0.57 & 0.49 & 0.57 & 0.63 \\
Mathematical Connection & 0.60 & 0.59 & 0.42 & 0.398
\end{tabular}

Bold size = Value of Squared Average Variance Extracted

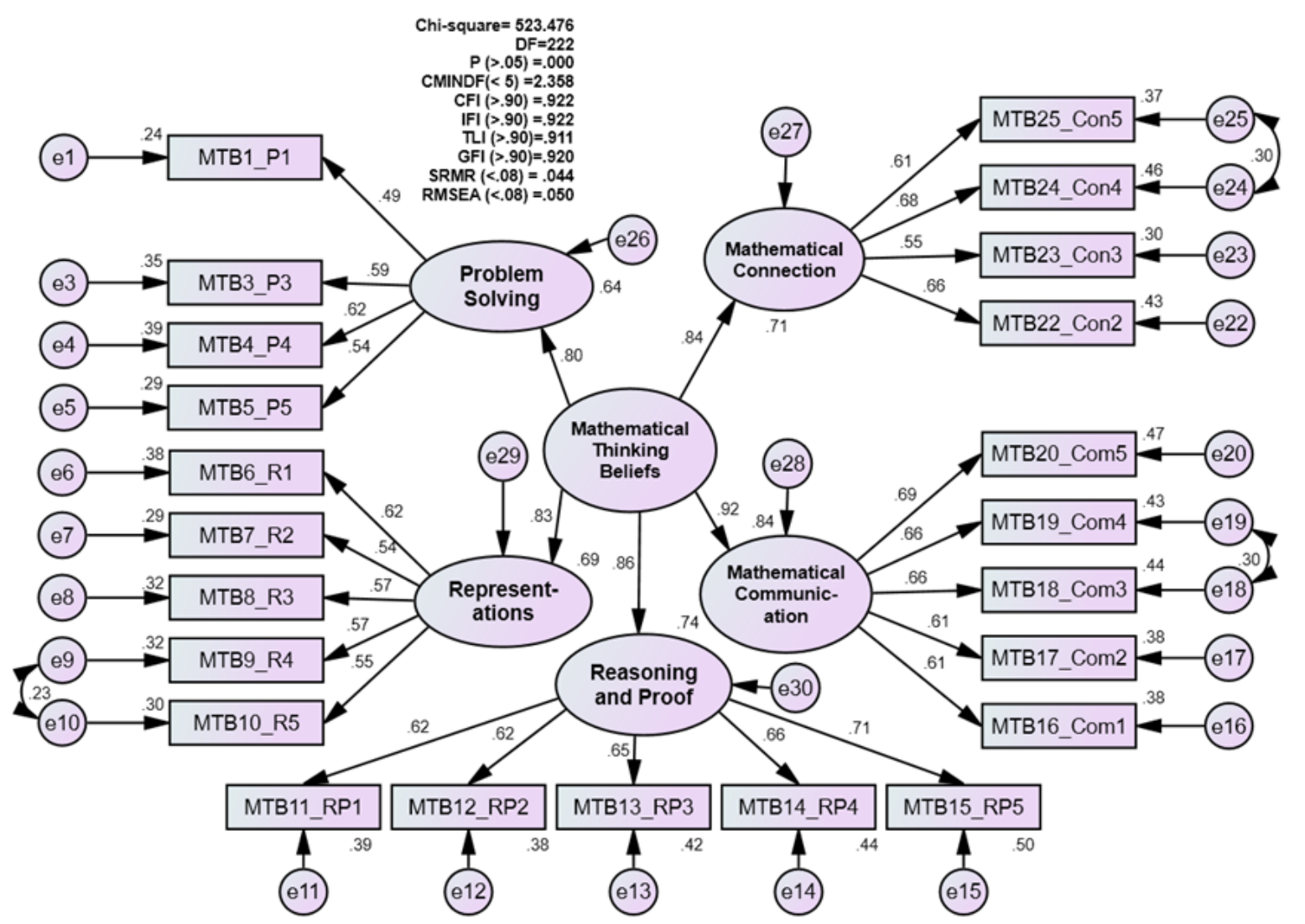

Figure 3. Second order of confirmatory factor analysis for MTB

As presented in Table 7, the Square Root of Average Variance Extracted (AVE) for each construct of the MTB was more than the Shared Variance (SV, Multiple Squared Correlation-SMC) except for a few relationships, establishing discriminant Validity for the model of MTB. The results indicated a significant relationship between the mathematical thinking skills.

As showed in Figure 3 and Table 4, the goodness fit indices for the second order of CFA for MTB. This revealed that the fit statistics are located within the acceptable criteria as Normed Chi-Squared CMINDF $=$ 2.358, CFI $=0.922, \mathrm{IFI}=0.922, \mathrm{TLI}=0.911, \mathrm{GFI}=0.920$, SRMR $=0.044$, and RMSEA $=050$. Finally, the magnitudes of higher loadings for the five sub-factors are statistically significant (T-value $\geq 1.964$ and P-value $\leq 0.05)$.

\section{Discussion}

This research aimed to develop an instrument for measuring teachers' mathematical thinking beliefs. It 
also aimed to test reliability, validity and G factor of SEM of teachers' mathematical thinking beliefs instrument. The current research used CFA to test the validity of an instrument to assess the mathematical thinking beliefs of mathematics teachers. The sample covered a sample of mathematics teachers from public schools in Oman. The instrument was developed as a model consisting of five factors: belief about problem solving, mathematical representations, reasoning and proofs, mathematical communications, and mathematical connections. The original scale contained 25 items with 5 items for each factor. After the testing of the scale using CFA, one item from the factor "problem solving" and one item from the factor "mathematical connections" were deleted, and the final scale resulted in 23 items. The results of the reliability test revealed that all factors reached the accepted reliability level, and the model met the good fit index of CFA. The finding of this study indicated evidence about the validity and reliability of the MTB scale and its benefit for measuring teachers' mathematical thinking beliefs, especially in Arab countries.

The results showed the relationships among all dimensions of teachers' mathematical thinking beliefs which were revealed about the consistence between the instrument's dimensions. This result supports the results that showed the goodness fit indices for the overall model. The results are consistence with previous researches' results which showed that there are relationships between the mathematical thinking skills. This can be explained from the effect of each skill on the other mathematical thinking skills. For example, problem-solving helps students build their new mathematical knowledge; this indicates a process of improving the mathematical knowledge which was one of the main objectives of teaching mathematics (NCTM, 2000). The results are on the line of Anderson (2009) which showed that problem solving improves the students' mathematical thinking. Palraj et al. (2017) showed that teachers' beliefs about problem solving affected their using of problem solving in their teaching practices. Yavuz and Cansiz (2019) showed that there is a strong relationship between students' mathematical thinking and their abilities to solve mathematical problems. Pourdavood et al. (2020) revealed that mathematical communications help to develop students' abilities in problem solving and reasoning. Ormond (2016) found that mathematical connections help students to gain the shared vision of mathematics which increases the growth of student's experience of solving problems in mathematics.

\section{CONCLUSION}

The analyses generated evidence that the Mathematical Thinking Beliefs instrument can be a suitable instrument to assess the mathematical thinking beliefs of mathematics teachers in the Arab area, especially in the Omani context. For the reason that all the factors indicate good and acceptable reliability values, each factor can be evaluated separately depending on the context of the research. Besides, since the MTB confirmed the model in this study as one of the first instruments for assessing teachers' beliefs about mathematical thinking, it can be used as a starting point for future research. The instrument can be used by teachers as self-assessment to assess their belief about mathematical thinking. Moreover, the institutes that are interested in teaching mathematics can apply the instrument to determine the teachers' beliefs before establishing the Professional development programs for mathematics teachers.

Author contributions: All authors have sufficiently contributed to the study, and agreed with the results and conclusions.

Funding: No funding source is reported for this study.

Acknowledgements: The authors would like to express special words of thanks and their acknowledgment to the Ministry of Education, Oman and Faculty of Education, Universiti Kebangsaan Malaysia (GG-2019-007).

Declaration of interest: No conflict of interest is declared by authors.

\section{REFERENCES}

Abdullah, A., Fadil, S., Abdurahman, S., \& Mohd, L. (2019). Emerging patterns and problems of higherorder thinking skills (HOTS) mathematical problem-solving in the form-three assessment (PT3). South African Journal of Education, 29(2), 1-18. https://doi.org/10.15700/saje.v39n2a1552

Acar-Erdol, T., \& Yildizl, H. (2018). Classroom assessment practices of teachers in Turkey. International Journal of Instruction 11(3), 587-602. https:// doi.org/10.12973/iji.2018.11340a

Aljaberi, N., \& Gheith, E. (2018). Ins-ervice mathematics teachers' beliefs about teaching, learning and nature of mathematics and their mathematics teaching practices. Journal of Education and Learning, 7(5), 156. https:/ / doi.org/10.5539/jel.v7n5p156

Alkharusi, H., Aldhafri, S., Al-Hosni, K., Al-Busaidi, S., Al-Kharusi, B., Ambusaidi, A., \& Alrajhi, M. (2017). Development and validation of a scale for measuring mathematics teaching self-efficacy for teachers in the Sultanate of Oman. International Journal of Instruction 10(3), 143-158. https:/ / doi.org/10.12973/iji.2017.10310a

Al-Mahrooqi, R., Denman, C., Al-Siyabi, J., \& AlMaamari, F. (2015). Characteristics of a good EFL Teacher: Omani EFL teacher and student perspectives. SAGE Open, 5(2), 1-15. https: / / doi.org/10.1177/2158244015584782

Anderson, J. (2009). Using NAPLAN items to develop students' thinking skills and build confidence. Australian Mathematics Teacher 65(4), 17-23.

Anthony, G., Hunter, J., \& Hunter, R. (2015). Supporting prospective teachers to notice students' 
mathematical thinking through rehearsal activities. Mathematics Teacher Education and Development 17(2), 7-24.

Bal, A. P. (2015). Examination of the mathematical problem-solving beliefs and success levels of primary school teacher candidates through the variables of mathematical success and gender. Kuram ve Uygulamada Egitim Bilimleri 15(5), 13731390.

Bates, A. B., Latham, N., \& Kim, J. (2011). Linking preservice teachers' mathematics self-efficacy and mathematics teaching efficacy to their mathematical performance. School Science and Mathematics 111(7), 325-333. https://doi.org/ 10.1111/j.1949-8594.2011.00095.x

Brady, K. (2014). Towards a fresh understanding of the relationship between teacher beliefs about mathematics and their classroom practices. In M. Anderson, M. Cavanagh, \& A. Prescott (Eds.), Proceedings of the 37th annual conference of the Mathematics Education Research Group of Australasia (pp. 103-110). MERGA.

Brown, T. A. (2014). Confirmatory factor analysis for applied research. Guilford Publications.

Burton, L. 1984. Mathematical thinking: The struggle for meaning. Journal for Research in Mathematics Education 15(1), 35-49. https://doi.org/10.5951/ jresematheduc.15.1.0035

Byrne, B. M. (2016). Structural equation modeling with AMOS: Basic concepts, applications, and programming. Routledge.

https://doi.org/10.4324/9781315757421

Celiki, H., \& Ozdemir, F. (2020). Mathematical thinking as a predictor of critical thinking dispositions of pre-service mathematics teachers. International Journal of Progressive Education, 16(4), 81-98. https:/ / doi.org/10.29329/ijpe.2020.268.6

Chigeza, P. (2013). Translating between and within representations: Mathematics as lived experiences and interactions. In V. Steinle, L. Ball, \& Bardini (Eds.), Proceeding of the 36th Annual Conference of Mathematics Education Group of Australia (pp. 178185). Mathematics Education Research Group of Australasia. MERGA.

Haciomeroglu, G. (2013). Mathematics anxiety and mathematical beliefs: What is the relationship in elementary pre-service teachers?. Undergraduate Mathematics Preparation of School Teachers 5, 1-9.

Hair, J. F., Black, W. C., Babin, B. J., \& Anderson, R. E. (2014). Multivariate data analysis. Pearson Education Limited.

Hongboontri, C., \& Keawkhong, N. (2014). School culture: Teachers' beliefs, behaviors, and instructional practices. Australian Journal of Teacher Education, 39(5), 66-88. https://doi.org/10.14221/ ajte.2014v39n5.7
Hudson, B., Henderson, S., \& Hudson, A. (2015). Developing mathematical thinking in the primary classroom: Liberating students and teachers as learners of mathematics. Journal of Curriculum Studies, 47(3), 374-398. https://doi.org/10.1080/ 00220272.2014 .979233

Karaman, P., \& Sahin, C. (2017). Adaptation of teachers' conceptions and practices of formative assessment scale into Turkish culture and a structural equation modeling. International Electronic Journal of Elementary Education, 10(2), 185-194. https://doi.org/10.26822/iejee.2017236114

Keith, T. Z., Fine, J. G., Taub, G. E., Reynolds, M. R., \& Kranzler, J. H. (2006). Higher order, multisample, confirmatory factor analysis of the wechsler intelligence scale for children (4th ed.): What does it measure? School Psychology Review, 35(1), 108-127.

Kline, R. B. (2015). Principles and practice of structural equation modeling. The Guilford Press.

Kul, U., \& Celik, S. (2017). Exploration of pre-service teachers' beliefs in relation to mathematics teaching activities in classroom-base. International Journal of Research in Education and Science (IJRES) 3(1), 245257.

Lesh, R., Cramer, K., Doerr, H., Post, T., \& Zawojewski, J. (2003). Model development sequences. In R. Lesh \& H. Doerr (Eds.), Beyond constructivism: A models and modelling perspective on mathematics problem solving; learning and teaching (pp. 35-58). Lawrence Erlbaum Associates, Inc. https://doi.org/10.4324/ 9781410607713

Lui, A. M., \& Bonner, S. M. (2016). Preservice and inservice teachers' knowledge, beliefs, and instructional planning in primary school mathematics. Teaching and Teacher Education, 56(2), 1-13. https:/ / doi.org/10.1016/j.tate.2016.01.015

Maoto, S., Masha, K., \& Mokwana, L. (2018). Teachers' learning and assessing of mathematical processes with emphasis on representations, reasoning and proof. Pythagoras, 39(1), a373. https://doi.org/ 10.4102/ pythagoras.v39i1.373

Mccluskey, C., Mulligan, J., \& Mitchelmore, M. (2016). The role of reasoning in the Australian curriculum: Mathematics. In B. White, M. Chinnappan, \& S. Trenholm (Eds.), Proceedings of the 39th annual conference of the Mathematics Education Research Group of Australasia (pp. 447-454). MERGA.

Memnun, S., \& Katranc, Y. (2012). A research on the beliefs about mathematics learning and teacher efficacy of prospective teachers in Turkey. World Journal of Education, 2(6), 66-78. https:// doi.org/10.5430/wje.v2n6p66

Mistima, S., Zakaria, E., \& Nordin, N. (2011). A confirmatory factor analysis of mathematics beliefs scale in a malaysian context. Australian Journal of Basic and Applied Sciences, 5, 555-560. 
Moss, C., \& Archer, J. (2014). Accreditation not aggravation. ALM International Journal 9(92), 79-83.

Mumcui, H. Y., \& Aktürk, T. (2017). An analysis of the reasoning skills of pre-service Teachers in the context of mathematical thinking. European Journal of Education Studies, 3(5), 225-254.

NCII. (2016). Principles for designing intervention in mathematics. Office of Special Education, U.S. Department of Education.

NCTM. (2000). Principles and standards for school mathematics. The National Council of Teachers of Mathematics, Inc.

OECD. (2000). The PISA 2000 assessment of reading, mathematical and scientific literacy.

Pajares, M. F. (1992). Teachers' beliefs and educational research: Cleaning up a messy construct. Review of Educational Research, 62(3), 307-332. https:/ / doi.org /10.3102/00346543062003307

Palraj, S., DeWitt, D., \& Alias, N. (2017). Teachers beliefs in problem solving in Rural Malaysian secondary schools. Malaysian Online Journal of Educational Technology, 5(4), 45-57.

Peker, M., \& Ulu, M. (2018). The effect of pre-service mathematics teachers' beliefs about mathematics teaching-learning on their mathematics teaching anxiety. International Journal of Instruction, 11(3), 249-264. https:/ / doi.org/10.12973/iji.2018.11318a

Philipp, R. (2007). Mathematics teachers' beliefs and affect. In F. K. Lester (Ed.), Second handbook of research on mathematics teaching and learning (pp. 257-315). Information Age Publishing Inc.

Philipp, R., Thanheiser, E., \& Clement, L. (2002). The role of a children's mathematical thinking experience in the preparation of prospective elementary school teachers. International Journal of Educational Research, 37(2), 195-210. https://doi.org/10.1016/ S0883-0355(02)00060-5

Pourdavood, R., McCarthy, K., \& McCafferty, T. (2020). The impact of mental computation on children's mathematical communication, problem solving, reasoning, and algebraic thinking. Athens Journal of Education, 7(3), 241-254. https:/ / doi.org/10.30958/ aje.7-3-1

Privitera, G. J. (2014). Survey and correlational research designs. In Research methods for the behavioral sciences (pp. 227-240).

Purnomo, Y. W. (2017). A scale for measuring teachers' mathematics-related beliefs: A validity and reliability study. International Journal of Instruction, 10(2), 2-38. https://doi.org/10.12973/iji.2017. $1022 \mathrm{a}$
Reyes-Cedeno, C. C., Rivas-Cun, H. I., EspinozaCevallos, C. E., \& Rojas-Garcia, C. R. 2019. Assessment of the practices for early mathematics thinking in preschools of Pasaje city, Ecuador. European Journal of Educational Research, 8(4), 10631070. https:/ / doi.org/10.12973/eu-jer.8.4.1063

Salazar, D. A. (2012). Enhanced-Group Moore Method: Effects on van Hiele Levels of Geometric Understanding, Proof-Construction Performance and Beliefs. US-China Education Review, 6, 594-605.

Saragih, S., \& Napitupulu, E. (2015). Developing student-centered learning model to improve high order mathematical thinking ability. International Education Studies, 8(6), 104-112. https://doi.org/ 10.5539/ies.v8n6p104

Siemon, D., Day, L., Stephens, M., Horne, M., Callingham, R., Watson, J., Seah, R., \& Siemon, D. (2017). Reframing mathematical futures: Using learning progressions to support mathematical thinking in the middle years. In A. Downton, S. Livy, \& J. Hall (Eds.), Proceedings of the 40th Annual Conference of the Mathematics Education Research Group of Australasia (pp. 646). MERGA.

Tabachnick, B. G., \& Fidell, L. S. (2007). Using multivariate statistics (5th ed.). Pearson Education, Inc.

Ünlü, M., \& Ertekin, E. (2013). The relationship between mathematics teaching self-efficacy and mathematics self-efficacy. Procedia - Social and Behavioral Sciences 106, 3041-3045. https:/ / doi.org/10.1016/j.sbspro.2013.12.350

Uyangör, S. M. (2019). Investigation of the mathematical thinking processes of students in mathematics education supported with graph theory. Universal Journal of Educational Research, 7(1), 1-9. https:/ / doi.org/10.13189/ujer.2019.070101

Xenofontos, C., \& Kyriakou, A. (2017). Prospective elementary teachers' beliefs about collaborative problem solving and dialogue in mathematics. Mathematics Teacher Education and Development, 19(2), 142-158.

Yavuz Mumcu, H., \& Cansız Aktaş, M. (2019). The effect of the use of mathematics course in terms of prospective teachers' attitudes toward mathematics and their beliefs on the nature, teaching, and learning of mathematics. Pegem Eğitim ve Öğretim Dergisi, 9(3), 697-728. https:/ / doi.org/10.14527/pegegog.2019.023

Yong, H., \& Sam, L. (2008). Implementing school-based assessment: The mathematical thinking assessment (MATA). Buku Koleksi Bahan Seminar Inovasi Pedagogi IPBL Tahun 2008, (pp. 73-88), Batu Lintang, Kuching, Sarawak, 28 August.

\section{http://www.ejmste.com}

